\title{
Extent and Drivers of Mycotoxin Contamination: Inferences from a Survey of Kenyan Maize Mills
}

\author{
S. K. Mutiga, V. Were, V. Hoffmann, J. W. Harvey, M. G. Milgroom, and R. J. Nelson
}

First, fifth, and sixth authors: School of Integrative Plant Sciences, Cornell University, Ithaca, NY 14853; second and fourth authors: Biosciences Eastern and Central Africa (BecA)-International Livestock Research Institute (ILRI), P.O. Box 30709, Nairobi 00100, Kenya; and third author: International Food Policy Research Institute, 2033 K Street NW, Washington DC 20006.

Accepted for publication 30 April 2014.

\begin{abstract}
Mutiga, S. K., Were, V., Hoffmann, V., Harvey, J. W., Milgroom, M. G., and Nelson, R. J. 2014. Extent and drivers of mycotoxin contamination: Inferences from a survey of Kenyan maize mills. Phytopathology 104:1221-1231.

The prevalence of aflatoxin and fumonisin was investigated in maize intended for immediate human consumption in rastern Kenya at a time in 2010 when an aflatoxin outbreak was recognized. Samples were collected from people who brought their maize for processing at local commercial mills. Sites were selected using a geographical information system overlay of agroecological zones and Kenya's administrative districts. Interviews and collection of maize flour samples was conducted from 1,500 people who processed maize at 143 mills in 10 administrative districts.

respectively. Samples with aflatoxin contamination above the legal limit ranged between 22 and $60 \%$ across the districts. A higher occurrence of aflatoxin was associated with smaller maize farms, lower grain yield, and monocropping systems, while a larger magnitude of the toxin was observed in the subhumid agroecological zone, in samples with more broken kernels, and, curiously, less maize ear damage at harvest. Analysis of paired grain samples (visually sorted and unsorted) showed that sorting reduced fumonisin by $65 \%$, from above to below the legal limit of 1,000 ppb. Sorting did not, however, reduce aflatoxin levels. Although the aflatoxin problem is widely acknowledged, the high prevalence of fumonisin has not previously been reported. There is need for surveillance of the two mycotoxins and establishment of intervention strategies to reach vulnerable small-scale farmers.
\end{abstract} Mycotoxins were analyzed using enzyme-linked immunosorbent assays for aflatoxin and fumonisin, leading to detection at levels above the respective maximum tolerable limits in 39 and $37 \%$ of the samples,
Additional keywords: maize contamination, public health, survey.
Maize (Zea mays L.) is the staple food of millions of people in sub-Saharan Africa, including $96 \%$ of the Kenyan population $(9,16)$. There has been increasing concern that African populations dependent on maize are at high risk of exposure to toxic fungal metabolites called mycotoxins (40,50). Mycotoxigenic fungi are endemic in tropical and subtropical environments, and maize is an excellent substrate for the aflatoxin-producing fungal species, Aspergillus flavus and A. parasiticus, and for the fumonisin-producing Fusarium verticillioides. Aflatoxin B1 (AFB1) and fumonisin $\mathrm{B} 1$ (FB1) are carcinogens $(33,40)$. Acute exposure to AFB1 is lethal, while chronic exposure can cause immunosuppression, liver cancer, impairment of nutrient absorption, and fetal and infant growth retardation (30). Chronic exposure to FB1 has been associated with esophageal cancer, growth retardation, and immunosuppression (49). Kenya has been shown to have a high prevalence of maize contamination with aflatoxin, and fatal aflatoxicosis is frequently reported in the country (35).

To reduce human exposure to mycotoxins, the United Nations' World Food Program and Kenya Bureau of Standards have stipulated maximum tolerable limits for aflatoxin in human food at 10 parts per billion ( $\mathrm{ppb}$ or $\mathrm{mg} / \mathrm{kg}$ ), and that of fumonisin at $1,000 \mathrm{ppb}$ (or 1 part per million [ppm]) $(13,44)$. In practice, such standards are rarely operationalized in the food systems of developing countries, such that $25 \%$ of the world's foodstuffs are suspected of being contaminated with mycotoxins (10). Surveillance of mycotoxins and other threats to food safety is difficult to

Corresponding author: R. J. Nelson; E-mail address: rjn7@ cornell.edu

http://dx.doi.org/10.1094/PHYTO-01-14-0006-R

(c) 2014 The American Phytopathological Society implement in the context of Africa's semisubsistence agriculture. Small-scale farmers produce $75 \%$ of Kenya's maize, using it for both home consumption and for trade $(36,47)$. The majority of the grain that is traded goes through informal markets consisting of small-scale traders and a few wholesalers who move the grain within the country (36). The maize value chain lacks a wellestablished mechanism to systematically test grain quality or safety. Most maize consumers practice visual inspection and sorting of grain prior to milling as the only quality check approach.

Hell and Mutegi (21) reviewed the pre- and postharvest maize management practices that influence mycotoxin accumulation in sub-Saharan Africa. Preharvest aflatoxin contamination has been associated with factors that overcome physical barriers to colonization (e.g., damage by birds and insects), that stress the plant (e.g., pest pressure and climatic and soil-related stress factors), or that cause spatiotemporal coincidence of a vulnerable host and the mycotoxigenic fungi (e.g., silking and harvesting time) $(17,20,42,45,46,48)$. The extent of postharvest toxin accumulation is influenced by the amount of inoculum and successful colonization at pre- and postharvest infection, timing of harvest, grain moisture (initial drying, protection and ventilation during storage), and kernel integrity (due to grain handling and pest damage) $(1,12,19,24,27,28)$. Among the many recognized drivers of aflatoxin accumulation, preharvest drought and postharvest moisture are considered the most critical.

Eastern Kenya is a drought-prone region that is recognized as an aflatoxin hotspot $(3,35)$. Acute aflatoxicosis has been observed mainly after periods of moisture stress during maize crop development, when rainfall occurs after the crop has attained physiological maturity and before it is harvested, and when a bumper crop is stored inadequately $(34,35)$. Although multiple factors 
could have influenced the observed aflatoxin contamination and aflatoxicosis, previous reports emphasized improper postharvest grain handling as causal factors $(3,13,29,35)$. Between 2004 and 2011, 477 cases of acute aflatoxicosis were reported in eastern Kenya, with $40 \%$ resulting in death (13). These tragic incidents are correlated with the area's favorable environmental conditions for A. flavus growth and mycotoxin production, as well as the presence of a highly toxigenic A flavus population (38). An aflatoxin outbreak occurred in 2010, a season of abundant rainfall and bounteous grain yield in eastern Kenya, and was recognized in the national and world news media (BBC 2010). To protect the population, the Government of Kenya prohibited the consumption or trade of $\approx 200,000$ tons of maize grain (BBC 2010) and offered to buy the contaminated grain at a reduced price. The 2010 aflatoxin outbreak was the context for the present study, which was part of a larger effort to assess the extent and drivers of mycotoxin contamination across diverse contexts.

For the majority of maize consumed in Kenya, the main point of value addition is the village-based hammer mill, known locally and hereafter as the posho mill $(15,26)$. Maize processed at these local mills may be from farmers' own stores, purchased from grain dealers, received as gifts from friends or relatives, or received as food aid. We focused our sampling on these microscale commercial mills because they process $\approx 60 \%$ of the maize consumed in Kenya and are convenient locations for collecting maize intended for immediate human consumption (26). We reasoned that posho mills represent suitable sites for mycotoxin surveillance and intervention. To test this idea, we investigated whether information gathered from posho mill customers would provide relevant insights related to mycotoxin contamination of maize. The issues of relevance included the extent of self-provisioning of maize, the drivers of contamination, and the effectiveness of preconsumption grain sorting.

\section{MATERIALS AND METHODS}

Study sites and sampling. Study sites were selected based on an overlay of administrative boundaries and agroecological zones (AEZs) for eastern Kenya using publicly available datasets that were retrieved by using ArcGIS (release 9.3; ESRI, Redlands, CA) and Manifold System (ver. 8; Manifold Software Limited, Wanchai, Hong Kong) geographical information systems (GIS) software. Ten study districts were randomly selected and their headquarters identified as the study hubs (Fig. 1). Maize-growing villages were identified with guidance from the local agricultural officers at their district headquarters. A subset of maize-growing villages was randomly selected across the AEZs. In each village, local commercial maize mills were randomly selected for sampling. The key descriptors of the AEZs, indicated in Table 1, are soil moisture availability index (\%) and annual rainfall range (22). The 10 administrative districts, AEZs, number of posho mills, and sample size are shown in Table 1. Machakos and Kitui districts in lower eastern Kenya, where high case-fatality rates of aflatoxicosis had been previously reported, were included.

Research assistants were recruited and centrally trained to conduct sampling and interviews. They then collected samples from

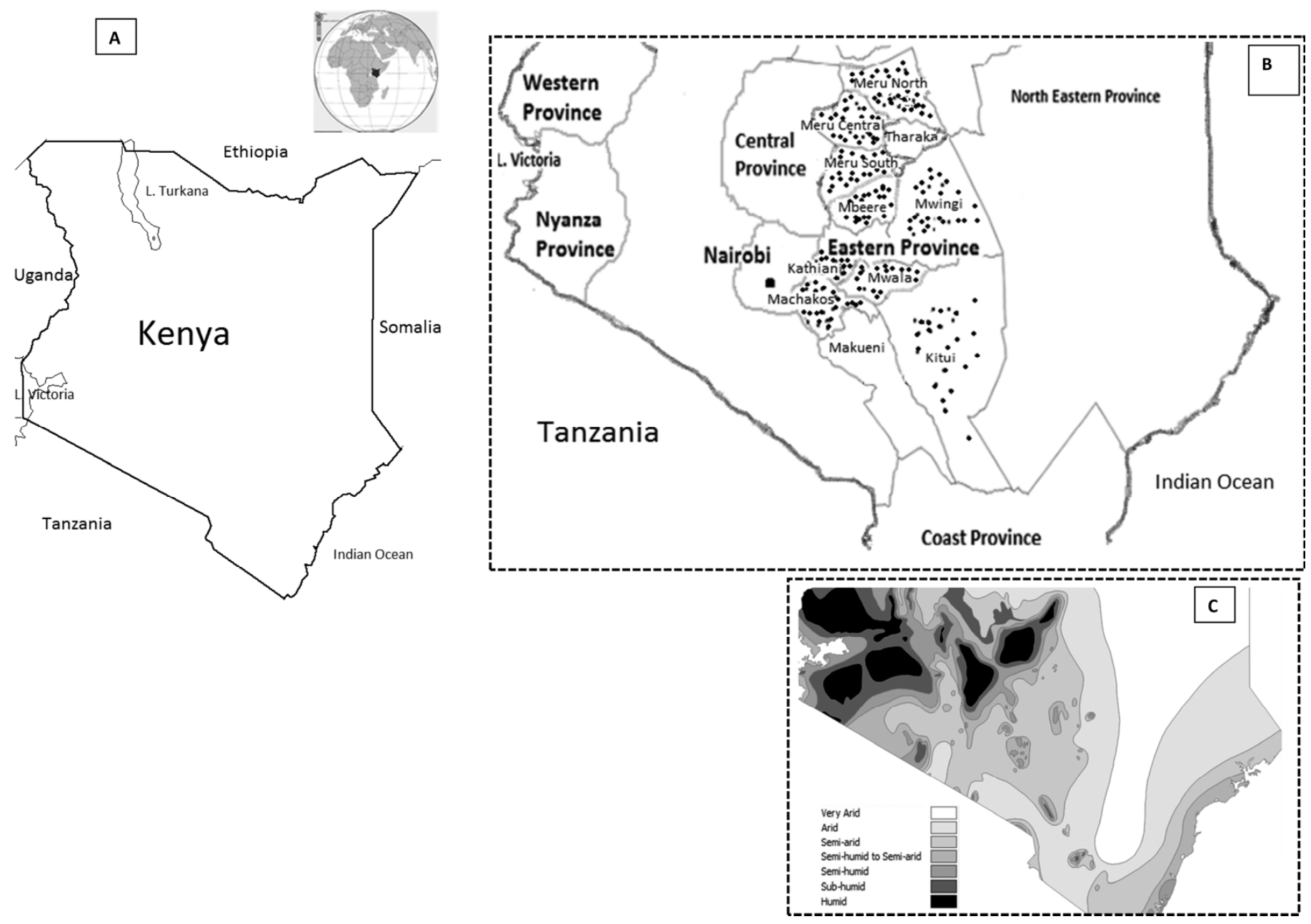

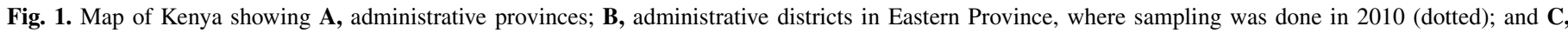

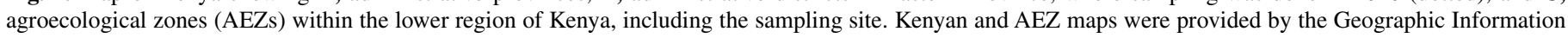
Systems lab at the International Livestock Research Institute, Nairobi, Kenya. 
people who came to process their maize at the posho mills. A survey instrument, which was exempted under study protocol number 100800162 of Cornell University Institutional Review Board for human participants in research, was used to collect information from the people who provided their maize samples. The survey covered how maize grain was acquired, the maize variety, intended use of flour, awareness about health problems associated with consumption of moldy grain, and pre- and postharvest maize cultivation and handling practices. Samples were collected from 10 to 30 customers at each of 143 posho mills. Maize flour samples, each weighing $\approx 35 \mathrm{~g}$, were collected into 50-ml Falcon tubes (BD, Franklin Lakes, NJ). To reduce moisture content in the samples and, thus, avoid further fungal growth, silica gel packs (Control Company, Houston) were added to the sample tubes, which were then capped and held at ambient temperature for a maximum of $72 \mathrm{~h}$ before they were transported to BecA-ILRI Hub, Nairobi, where they were stored at $4^{\circ} \mathrm{C}$ until analysis.

Sample preparation and mycotoxin analysis. Aflatoxin was extracted from 5-g subsamples of maize flour using $70 \%$ methanol and analyzed with a commercially available enzyme-linked immunosorbent assay (ELISA) kit following the manufacturer's protocol (Helica Biosystems Inc., Fullerton, CA). The solid-phase direct competitive aflatoxin ELISA kit (Helica catalog number 941BAFL01-96) consisted of a 96-well microplate coated with an antibody that was optimized to cross-react with the four aflatoxin types at the following rates: B1 (100\%), B2 (77\%), G1 (64\%), and G2 (25\%). The lower and upper limits of quantification of the kit were 1 and $20 \mathrm{ppb}$, respectively, based on information provided by the supplier; samples with toxin values below the limit of quantification were considered as containing no detectable toxin.

Fumonisin was extracted from $10 \mathrm{-g}$ subsamples of maize flour using $90 \%$ methanol and analyzed with a commercially available ELISA kit following the manufacturer's protocol (Helica Biosystems, Inc.). The solid-phase direct competitive fumonisin ELISA kit (Helica catalog number 951FUM01C-96) consisted of a polystyrene 96 -well microplate coated with an antibody that was optimized to cross-react with three fumonisin subtypes (B1, B2, and B3). The lower and upper limits of quantification of the kit were 100 and 6,000 ppb, respectively, based on information provided by the supplier.

Optical densities of the reactions for the two mycotoxins were quantified using a microplate reader (BioTek Instruments, Inc., Winooski, VT) with an absorbance filter of $450 \mathrm{~nm}$. Test values were interpreted with reference to standards that were included in each experiment. Samples with estimated aflatoxin concentration $>20 \mathrm{ppb}$ were diluted with the extraction solvent and reassessed. A subset of samples $(628$ of 1,500$)$ previously analyzed for afla- toxin were selected for fumonisin analysis based on the following criteria: all samples $(n=333)$ with aflatoxin $>20 \mathrm{ppb}$ (the Kenyan aflatoxin legal limit in food at the time of the study; the legal limit was recently revised to $10 \mathrm{ppb}$ ) were included, while the remainder was selected to equally represent the aflatoxin bins 0 to 5,5 to 10,10 to 15 , and 15 to $20 \mathrm{ppb}$. For each aflatoxin bin, $\approx 70$ samples were chosen to represent equal proportions of samples collected from each AEZ. Samples with estimated fumonisin above the upper limit of quantification of the kit were not reassessed, but were reported as "above 6,000 ppb".

Aflatoxin ELISA validation. The aflatoxin ELISA method was validated by reanalyzing 35 samples using ELISA and the Vicam AflaTest (Watertown, MA, USA), a flourometric-immunocapture assay. Because the two methods have different protocols, a harmonized extraction protocol was established as follows: $\mathrm{NaCl}$ was added to a maize flour sample in a ratio of 1:10 per the AflaTest protocol, and $80 \%$ methanol was used as the extraction solvent with a ratio of maize flour to extraction solvent of 1:5 (wt/vol) (per Helica Biosystems's ELISA protocol). The slurry was mixed in an incubator shaker at $225 \mathrm{rpm}$ for $4 \mathrm{~min}$ at $25^{\circ} \mathrm{C}$, and the mixture was allowed to settle for $15 \mathrm{~min}$ prior to filtering through a Whatman filter paper number 1 . From the above extract, a 100- $\mu$ l aliquot was directly analyzed per the ELISA protocol, while $2 \mathrm{ml}$ was diluted in distilled water (1:4) and analyzed using the Vicam AflaTest method.

Scoring for maize kernel type, quality, and grain sorting. To investigate the effect of grain sorting based on visual quality, we scored all grain before and after sorting at a mill, prior to sample collection. We developed a grain score scale and a corresponding pictorial guide. The grain characteristics scored were kernel texture or type (e.g., flint or dent) $(5,6)$; percentage of broken kernels in a sample (kernel breakage); and moldiness, discoloration, and rottenness (moldiness). The kernel texture score scale was $1=$ flint, $2=$ semiflint, $3=$ semident, $4=$ dent, and $5=$ mixed. The scale for kernel breakage was $1=<1,2=1$ to $10,3=10$ to 50 , $4=50$ to 90 , and $5=>90 \%$ broken kernels. The scale for moldiness was $1=<1,2=1$ to $10,3=10$ to $50,4=50$ to 90 , and $5=>90 \%$ of grain moldy, discolored, or rotten.

To investigate whether sorting maize grain before milling reduced aflatoxin and fumonisin, we collected an additional 62 pairs of unsorted and sorted maize grain in the year 2012 at five posho mills in Machakos district. These samples were scored for kernel breakage and moldiness prior to milling using a Romer Mill (Union, MO) and conducting mycotoxin analysis.

Statistical analysis. For establishment of aflatoxin predictors, a two-part analysis was adopted. First, aflatoxin values $<1 \mathrm{ppb}$ were coded 0 ; while those $>1 \mathrm{ppb}$ were coded 1 and these scores were used in a generalized linear mixed-model PROC GLIMMIX with

TABLE 1. Descriptors of agroecological zones (AEZs) and number of posho mills and samples across AEZs and districts in eastern Kenya

\begin{tabular}{|c|c|c|c|c|c|}
\hline & \multicolumn{5}{|c|}{ Agroecological zone (AEZ) } \\
\hline & Humid & Subhumid & Semihumid & Semihumid to semiarid & Semiarid \\
\hline Rainfall (mm/PA) & $1,100-2,700$ & $1,000-1,600$ & $800-1,400$ & $600-1,100$ & $450-900$ \\
\hline Soil moisture availability index $(\%)$ & $>80$ & $65-80$ & $50-65$ & $40-50$ & $25-40$ \\
\hline Number of mills sampled & 18 & 29 & 20 & 31 & 45 \\
\hline \multicolumn{6}{|l|}{ District (number of samples) ${ }^{\mathrm{z}}$} \\
\hline Embu & 50 & 10 & 80 & $\ldots$ & 10 \\
\hline Kathiani & $\ldots$ & $\ldots$ & 40 & 110 & $\ldots$ \\
\hline Kitui & $\ldots$ & $\ldots$ & $\ldots$ & $\ldots$ & 150 \\
\hline Machakos & $\ldots$ & $\ldots$ & 60 & 60 & 30 \\
\hline Mbeere & 20 & $\ldots$ & 20 & 80 & 30 \\
\hline Meru central & 60 & 90 & $\ldots$ & $\ldots$ & $\ldots$ \\
\hline Meru north & 10 & 140 & $\ldots$ & $\ldots$ & $\ldots$ \\
\hline Meru south & 30 & 80 & $\ldots$ & 40 & $\ldots$ \\
\hline Mwala & $\ldots$ & $\ldots$ & $\ldots$ & 10 & 140 \\
\hline Mwingi & $\ldots$ & $\ldots$ & $\ldots$ & 40 & 110 \\
\hline Total & 170 & 320 & 200 & 340 & 470 \\
\hline
\end{tabular}

${ }^{\mathrm{z}}$ Number of samples collected per AEZ within districts. 
a LOGIT function for prediction of presence or absence of aflatoxin in SAS (SAS Institute Inc., Cary, NC). Second, aflatoxin values $>1 \mathrm{ppb}$ were logarithmically transformed and the data were used in a mixed model for accumulation of aflatoxin in PROC MIXED in SAS. In the two models, "Mill", "Village", and "District" were considered as random effects, because the chosen mills were a sample from a larger population of mills within villages and districts. All other factors were considered fixed in the models. Because the questionnaire had many variables, fixed factors were entered and removed sequentially until the model with statistically significant factors was identified. For the PROC MIXED model, least square means of the statistically significant factors were separated by Tukey's honestly significant difference method, and back-transformed to geometric means (GMs) of the aflatoxin levels. For a subset of samples, we used a paired $t$ test and correlation analysis to compare the aflatoxin and fumonisin levels, kernel breakage, and moldiness before and after grain sorting. Spearman's correlation tests were done in pairwise comparisons of highly skewed data or data that did not meet the criteria of Pearson's correlation test.

\section{RESULTS}

In this study, milled maize samples $(n=1,500)$ were collected from posho mills $(n=143)$ in 2010. For each maize sample, a corresponding questionnaire was completed, providing data on biophysical and socioeconomic context. Among the 1,500 samples collected, $867(57 \%)$ of the samples were said to have been produced by the household that would consume the grain ("home-grown"). The majority of the home-grown maize ( $n=$ $728,84 \%$ ) had been cultivated on farms of up to 1 ha. This article reports mycotoxin prevalence on maize samples (aflatoxin, $n=$ 1,500; fumonisin, $n=628$ ), and the associations between aflatoxin and farming conditions and practices for data from home-grown maize. Each sample was analyzed for aflatoxin content and a subset of samples was analyzed for fumonisin content. The questionnaire factors that were not found to be statistically associated or did not improve the model for aflatoxin presence or level were dropped. Supplemental samples of whole grain $(n=62)$ were collected (before and after sorting) at five mills in 2012 and were used to evaluate the effectiveness of grain sorting for reducing mycotoxin levels. The validity of the commercial ELISA kit for aflatoxin quantification was confirmed by comparison of results with an independent assay procedure based on flourometricimmunocapture. Pearson correlation analysis (using a harmonized extraction protocol) of the ELISA assay with the Vicam AflaTest showed a highly significant correlation $(r=0.96, P<0.0001)$ between the two methods for samples with aflatoxin levels between 0 and 1,500 ppb.
Prevalence and relationship of occurrences of aflatoxin and fumonisin. All districts and AEZs had samples with aflatoxin or fumonisin levels above the limit allowed in human food (Table 2; Fig. 2). The percentage of samples with detectable aflatoxin ranged from $46 \%$ (Kathiani) to $85 \%$ (Mwala) (Table 2). The proportion of samples $>10 \mathrm{ppb}$ was 22 to $60 \%$ across districts. Districts with previously reported cases of aflatoxicosis fatalities such as Machakos, Mwala, and Kitui had lower aflatoxin ranges than those found in the three Meru districts (Table 2). For fumonisin, the proportion of detectably contaminated samples was $69 \%$ (Mwala) to $87 \%$ (Meru North), and the proportion of samples exceeding the legal limit of $1,000 \mathrm{ppb}$ was 22 to $59 \%$ across districts. Interestingly, Mwala had the highest proportion of aflatoxin-contaminated samples (85\%) and the lowest proportion of samples exceeding $1,000 \mathrm{ppb}$ of fumonisin-contamination (22\%) (Table 2).

The levels of mycotoxin contamination varied across AEZs (Fig. 2). The two mycotoxins showed contrasting distributions. Levels of aflatoxin contamination over the legal limit showed a bimodal pattern relative to moisture level; the highest were observed in the subhumid and semiarid zones. In contrast, fumonisin levels showed a unimodal pattern relative to moisture levels, with the highest levels observed in the semihumid zones, which had the lowest level of aflatoxin contamination above the legal limit (Fig. 2). A low but significant positive correlation was detected between aflatoxin and fumonisin occurrences $(\rho=0.15, P<$ 0.001 ). A test of independence conducted using paired levels of aflatoxin and fumonisin (coded as undetectable, between detectable and legal limit, and over the legal limit) returned a significant $\chi^{2}$ value $\left(\chi^{2}=18.87, d f=4, P<0.001\right)$, indicating a nonindependence of the occurrence of the two mycotoxins (Fig. 3).

Factors associated with the presence and quantity of aflatoxin in maize. Aflatoxin data were not normally distributed; out of 1,500 samples, one-third $(n=499)$ did not have detectable aflatoxin. A two-part analysis of factors for contamination was conducted, first for the binary presence or absence, and the second for continuous data (quantitative, detectable aflatoxin levels). Factors that were significantly associated with aflatoxin presence included grain yield, cropping system, and size of maize farm (Table 3). Maize obtained from people who intercropped their maize had significantly lower likelihood of aflatoxin contamination compared with those who practiced monocropping (odds ratio $=0.65, P=0.048$ ) (Table 3 ). Having more land cultivated with maize was associated with reduced likelihood of aflatoxin contamination. A 1-ha increase in land size cultivated with maize was associated with a $6 \%$ decrease in probability of contamination (Table 3). Farmers who had higher grain yields had lower probabilities of aflatoxin contamination. A $1 \mathrm{t} / \mathrm{ha}$ increase in grain yield was associated with a $15 \%$ reduction in probability of

TABLE 2. Percentage of samples with aflatoxin and fumonisin at different contamination categories per district ${ }^{\mathrm{y}}$

\begin{tabular}{|c|c|c|c|c|c|c|c|c|c|c|}
\hline \multirow[b]{3}{*}{ District } & \multicolumn{5}{|c|}{ Aflatoxin } & \multicolumn{5}{|c|}{ Fumonisin } \\
\hline & \multirow[b]{2}{*}{ Range $(\mathrm{ppb})^{\mathrm{z}}$} & \multicolumn{4}{|c|}{ Samples in aflatoxin (ppb) category $(\%)$} & \multirow[b]{2}{*}{ Range $(\mathrm{ppb})^{\mathrm{z}}$} & \multicolumn{4}{|c|}{ Samples in fumonisin (ppb) category $(\%)$} \\
\hline & & $<1$ & $1-10$ & $>10$ & $n$ & & $<100$ & $100-1,000$ & $>1,000$ & $n$ \\
\hline Meru central & $52-4,839$ & 20 & 20 & 60 & 150 & $2,040->6,000$ & 27 & 36 & 37 & 86 \\
\hline Mwala & $13-1,110$ & 15 & 30 & 55 & 150 & $842-4,809$ & 31 & 46 & 22 & 54 \\
\hline Meru north & $23-1,373$ & 27 & 27 & 45 & 150 & $2,300->6,000$ & 13 & 39 & 48 & 54 \\
\hline Meru south & $25-2,285$ & 23 & 35 & 43 & 150 & $1,596->6,000$ & 18 & 48 & 34 & 60 \\
\hline Mwingi & $16-395$ & 35 & 27 & 38 & 150 & $2,562->6,000$ & 16 & 25 & 59 & 56 \\
\hline Kitui & $15-1,024$ & 27 & 36 & 37 & 150 & $1,459 \rightarrow 6,000$ & 30 & 36 & 35 & 61 \\
\hline Mbeere & $15-989$ & 39 & 28 & 33 & 150 & $1,711->6,000$ & 14 & 41 & 44 & 70 \\
\hline Embu & $15-695$ & 42 & 27 & 31 & 150 & $1,300->6,000$ & 21 & 47 & 32 & 78 \\
\hline Machakos & $9-1,135$ & 50 & 27 & 23 & 150 & $974->6,000$ & 20 & 57 & 24 & 51 \\
\hline Kathiani & $8-1,133$ & 54 & 24 & 22 & 150 & $1,346-3,679$ & 17 & 44 & 39 & 54 \\
\hline
\end{tabular}

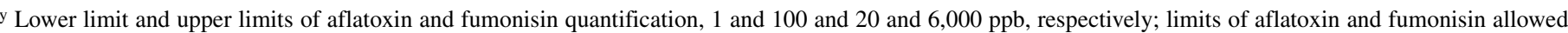
in human food, 10 and 1,000 ppb, respectively.

z Top quartile range. 
contamination (Table 3). Intercropping was not dependent on land size or grain yield. The $24 \%$ of the farmers who grew maize in a monocrop had less land cultivated with maize and higher grain yield (1.3 ha; $1.9 \mathrm{t} / \mathrm{ha})$ compared with the $67 \%$ who practiced intercropping (1.8 ha; $1.6 \mathrm{t} / \mathrm{ha})$. Although we hypothesized that AEZs would influence aflatoxin presence, the association was only marginal at a significance level of $\alpha=0.1$ for the joint effect of the five AEZ indicators. The odds ratio for aflatoxin presence differed significantly $(P=0.013)$ between subhumid and semihumid zones.

Major factors influencing the amount of aflatoxin in maize were predicted in a mixed model whose power was $23 \%\left(r^{2}=\right.$ $0.23, n=520$ ). The estimated mean aflatoxin (in logarithms and geometric levels) as well as confidence intervals by category for the factors found to be significant predictors of contamination are shown in Table 4. Random variables District, Village [District], and Mill [Village, District]) accounted for $11 \%$ of random variation. The key factors that were significantly associated with the observed aflatoxin levels included AEZs, kernel breakage, and percentage of damaged maize ears at harvest (Table 4). We ob- served a significant association between aflatoxin level and AEZ $(P<0.05)$. The highest GM aflatoxin $(44 \mathrm{ppb})$ was observed in the subhumid zone, which differed significantly $(P<0.05)$ from the rest of the zones. The drought-prone semiarid zone had the second highest aflatoxin contamination $(\mathrm{GM}=24 \mathrm{ppb})$, which did not differ significantly from the rest of the AEZs. All AEZs had GM aflatoxin above the legal limit of $10 \mathrm{ppb}$ (Table 4).

Aflatoxin level was significantly associated with kernel breakage $(P<0.05)$. The majority of the samples had $<1 \%$ broken kernels $(n=-319$, or $71 \%)$. This category had significantly lower aflatoxin levels $(\mathrm{GM}=18 \mathrm{ppb})$ than the two higher breakage categories ( 1 to $10 \%$ broken kernels, $n=121$; or $26 \%$ and 10 to $50 \%$ broken kernels, $n=12$ or $3 \%$ ). The samples scored as having 1 to $10 \%$ broken kernels were not significantly more contaminated than those scored as having 10 to $50 \%$ broken kernels ( $\mathrm{GM}=27$ and $30 \mathrm{ppb}$, respectively for the two sets). No samples were found to have $>50 \%$ of broken kernels. Samples from people who reported fewer damaged maize ears at harvest had the highest aflatoxin $(\mathrm{GM}=43 \mathrm{ppb})$, while samples from those who reported the highest maize ear damage had least aflatoxin $(\mathrm{GM}=$

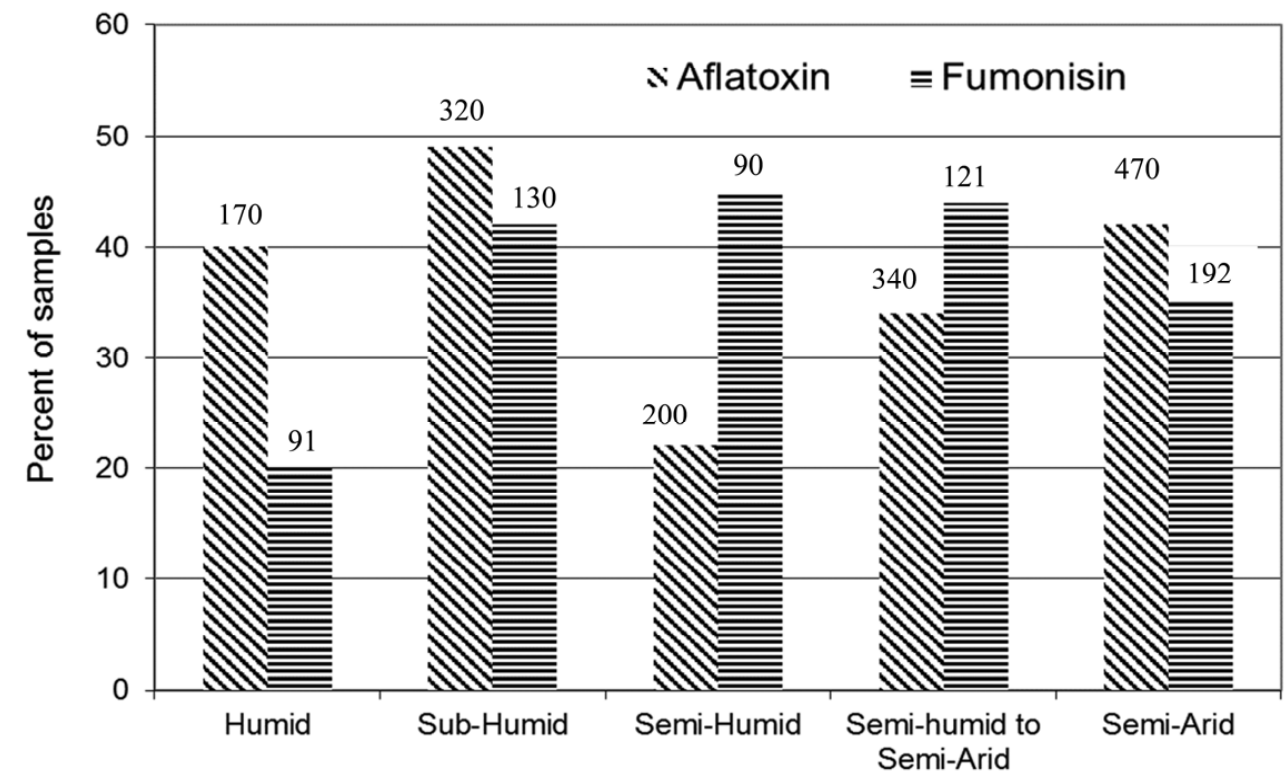

Fig. 2. Percentage of samples with mycotoxins above the legal limits in the five agroecological zones. Number of samples analyzed for each toxin in each agroecological zone is shown over the bars.

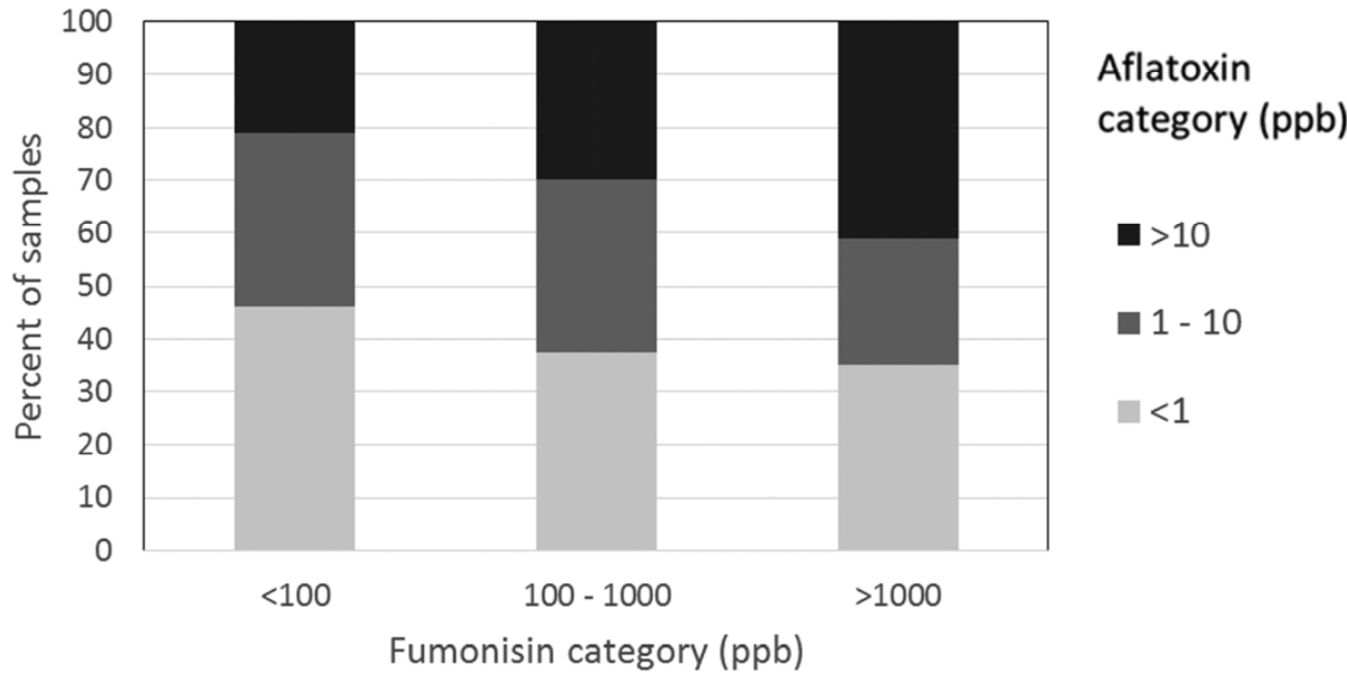

Fig. 3. Mosaic plot of percentage of samples with aflatoxin and fumonisin at different contamination categories $(n=628)$. 
$14 \mathrm{ppb})$. Aflatoxin levels in samples obtained from consumers who reported fewer damaged maize ears at harvest differed significantly $(P<0.05)$ from the rest of the ear damage categories. GM aflatoxin levels for all categories of kernel breakage and ear damage were $>10 \mathrm{ppb}$ (Table 4).

Grain visual assessment and sorting for mycotoxin removal. The visual scores of grain moldiness before and after sorting were highly correlated $(\rho=0.92, P<0.0001)$, as were the scores of kernel breakage before and after grain sorting $(\rho=0.94, P<$ 0.0001) (Table 5). Samples with the most broken kernels were not the moldiest, as indicated by a marginally significant correlation between scores of kernel breakage and moldiness (Table 5). Grain sorting reduced the percentage of broken kernels $(t=-3.35, d f=$ $810, P<0.001)$ but did not significantly reduce the percentage of moldy grains $(t=-1.02, d f=810, P=0.308)$ (Table 6). Sorting did not cause a significant shift in kernel breakage score. Grain sorting caused a general change in the visual appearance of the grain, decreasing the proportion of moldy or broken samples (Fig. 4). Kernel texture was scored in all whole-grain maize samples prior to sampling of the corresponding flour but no significant association was observed between this maize trait and aflatoxin.

Neither moldiness nor kernel breakage were correlated with aflatoxin (Table 5). A presorting score of moldiness was correlated with presorting fumonisin contamination $(\rho=0.42, P<$
0.001). A presorting score of kernel breakage was only marginally associated with presorting fumonisin level $(\rho=0.17, P<0.05)$ (Table 5). Grain sorting significantly reduced fumonisin $(t=-3.4$, $d f=50, P=0.001)$ but not aflatoxin levels $(t=-0.07, d f=50, P=$ 0.943 ) (Table 6). Grain sorting caused a $65 \%$ (900 ppb) reduction in fumonisin levels from above to below the legal limit of 1,000 $\mathrm{ppb}$, and significantly reduced samples above the limit from 48 to $22 \%$ (Table 6; Fig. 5).

\section{DISCUSSION}

This study used a novel approach to explore the extent of an aflatoxin outbreak in eastern Kenya and to assess its drivers during the course of a recognized outbreak by assessing aflatoxin contamination at local mills. We also provide evidence for widespread fumonisin contamination in the same maize samples. This region's frequent outbreaks of aflatoxicosis have caught the attention of policy makers, researchers, and other stakeholders but the fumonisin problem has not been recognized $(16,27)$. The most thorough previous analysis of aflatoxin contamination in eastern Kenya was conducted by Daniel et al. (13), who collected between 165 and 300 samples per year from households in two districts (Makueni and Kitui) over a 3-year period (Table 1). High levels of contamination were found in all years, with the propor-

TABLE 3. Estimates of effects of factors associated with presence of aflatoxin in maize ${ }^{\mathrm{x}}$

\begin{tabular}{|c|c|c|c|c|c|}
\hline Category $y$ & Estimate $(\mathrm{SE})^{\mathrm{z}}$ & $d f$ & $t$ value & $P>|t|$ & Odds ratio \\
\hline \multicolumn{6}{|l|}{ Agroecological zone } \\
\hline Humid & $-0.41(0.50)$ & 74.75 & -0.82 & 0.412 & 0.66 \\
\hline Semihumid & $-1.33(0.50)$ & 27.85 & -2.65 & 0.013 & 0.26 \\
\hline Semihumid to semiarid & $-0.60(0.46)$ & 25.53 & -1.32 & 0.199 & 0.55 \\
\hline Semiarid & $-0.07(0.45)$ & 13.15 & -0.16 & 0.878 & 0.93 \\
\hline \multicolumn{6}{|l|}{ Cropping system } \\
\hline Intercrop & $-0.42(0.21)$ & 813 & -1.98 & 0.048 & 0.65 \\
\hline Land size & $-0.06(0.03)$ & 341.1 & -1.98 & 0.049 & 0.94 \\
\hline Yield (t/ha) & $-0.16(0.06)$ & 813 & -2.48 & 0.014 & 0.85 \\
\hline
\end{tabular}

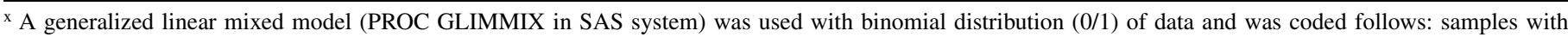
aflatoxin $<1 \mathrm{ppb}$ were assigned 0 ; and those with aflatoxin $\geq 1 \mathrm{ppb}$ were assigned 1. "District", "Village", and "Mill" were included in the two models as random effects and Mill was nested in Village within a District.

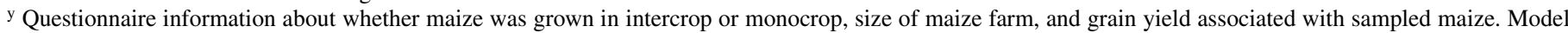
reference categories: Agroecological zone $=$ Subhumid and Cropping system $=$ Monocrop

${ }^{\mathrm{z}} \mathrm{SE}=$ standard error of the mean.

TABLE 4. Factors associated with amount of aflatoxin in home-grown maize

\begin{tabular}{|c|c|c|c|c|c|}
\hline \multirow[b]{3}{*}{ Factor, category } & \multirow[b]{3}{*}{$n$} & \multicolumn{4}{|c|}{ Aflatoxin (ppb) } \\
\hline & & \multirow[b]{2}{*}{$\log$ AFL } & \multicolumn{3}{|c|}{ GM and confidence interval $(95 \%)$} \\
\hline & & & GM & Lower & Upper \\
\hline \multicolumn{6}{|l|}{ Ear damage at harvest ${ }^{\mathrm{z}}$} \\
\hline Fewer damaged ears than usual & 14 & $3.8 \mathrm{~A}$ & 43.1 & 20.1 & 92.3 \\
\hline About the same damage as usual & 29 & $3.0 \mathrm{AB}$ & 19.6 & 11.6 & 33.3 \\
\hline More damaged ears than usual & 254 & $2.6 \mathrm{~B}$ & 14.1 & 10.3 & 19.3 \\
\hline Don't know & 218 & $3.4 \mathrm{~A}$ & 28.9 & 16.5 & 50.6 \\
\hline \multicolumn{6}{|l|}{ Kernel breakage after sorting } \\
\hline$<1 \%$ & 319 & $2.9 \mathrm{~B}$ & 17.5 & 13.2 & 23.3 \\
\hline 1 to $10 \%$ & 121 & $3.3 \mathrm{~A}$ & 26.9 & 19.0 & 38.2 \\
\hline 10 to $50 \%$ & 12 & $3.4 \mathrm{AB}$ & 30.1 & 13.3 & 68.4 \\
\hline \multicolumn{6}{|l|}{ Agroecological zone } \\
\hline Humid & 61 & $3.0 \mathrm{~B}$ & 19.9 & 11.7 & 33.8 \\
\hline Subhumid & 123 & $3.8 \mathrm{~A}$ & 43.9 & 27.9 & 69.1 \\
\hline Semihumid & 46 & $2.9 \mathrm{~B}$ & 17.7 & 9.5 & 33.1 \\
\hline Semihumid to semiarid & 104 & $3.1 \mathrm{~B}$ & 22.8 & 14.7 & 35.5 \\
\hline Semiarid & 180 & $3.2 \mathrm{~B}$ & 23.6 & 15.4 & 36.2 \\
\hline
\end{tabular}


tion of contaminated samples higher when a recognized outbreak was in progress. Sampling from local hammer mills in the present study allowed us to extend the spatial and temporal coverage of the aflatoxin analysis. We analyzed 1,500 maize samples from 10 districts for aflatoxin levels over a 2-month period, and determined fumonisin levels for a subset of $n=628$. Our findings confirm and extend the picture of aflatoxin contamination, with some of the new areas sampled showing the highest levels of aflatoxin contamination. In vitro studies with model organisms have shown that combined ingestion of aflatoxin and fumonisin can increase chances of liver cancer (16). If the results are applicable to humans, the observed widespread fumonisin contamination means that the maize-consuming population of eastern
Kenya faces more of a health threat than originally thought. Taken together, these findings confirm the need for surveillance and management of mycotoxins in maize in this region.

Mycotoxin surveillance and management strategies should target the most relevant points in the maize value chain. Given the high costs of aflatoxin analysis and the skewed distribution of contamination, sampling is inherently difficult for aflatoxin $(21,31)$. Surveillance and management is particularly problematic in the African context, where the majority of smallholder farmers consume maize produced on their own farms. In this survey, $57 \%$ of the samples collected at local mills had been grown by the household that would consume the grain, and the majority of the samples $(84 \%)$ had been cultivated on farms of $<1$ ha. A high
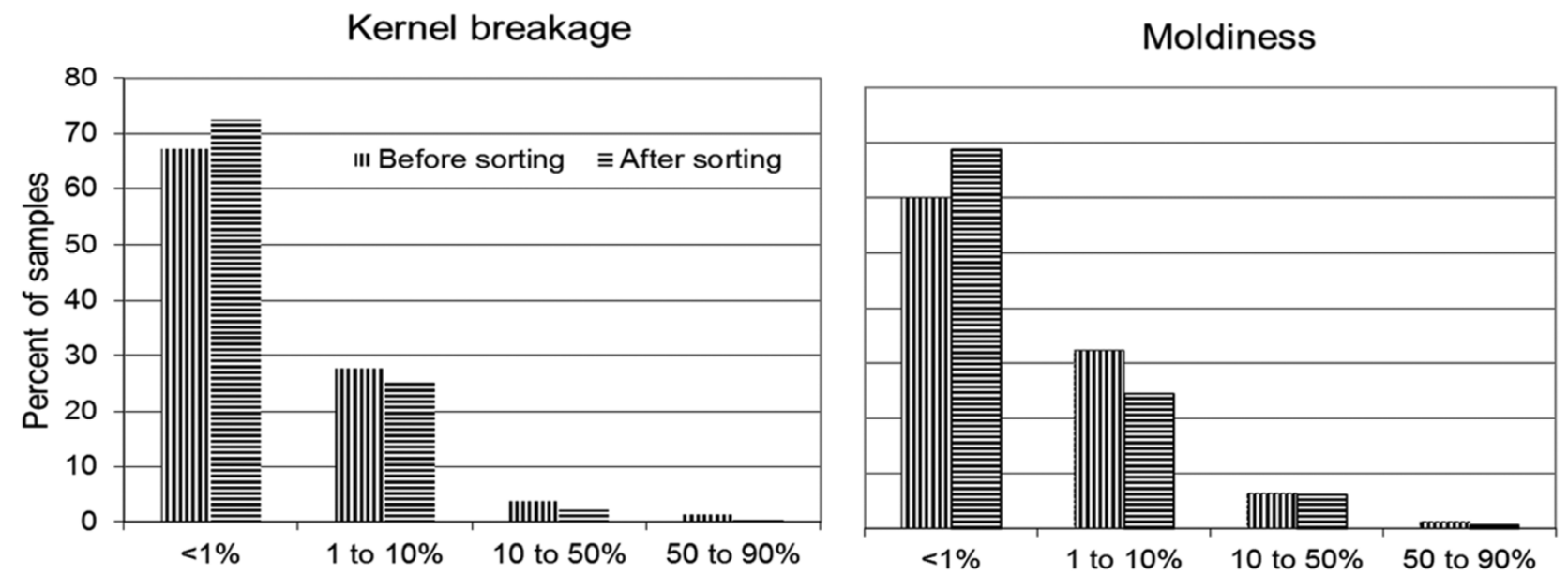

Fig. 4. Effect of sorting on kernel breakage and moldiness. Grain samples were visually scored at sampling sites. Y-axis = percentage of samples in grain quality category; $n=822$. X-axis = grain score scale, where $1=<1,2=1$ to $10,3=10$ to $50,4=50$ to 90 , and $5=>90 \%$ broken, moldy, discolored, or rotten kernels in a sample.

TABLE 5. Pairwise correlations among grain quality scores and mycotoxin levels before and after visual sorting of maize ${ }^{\mathrm{x}}$

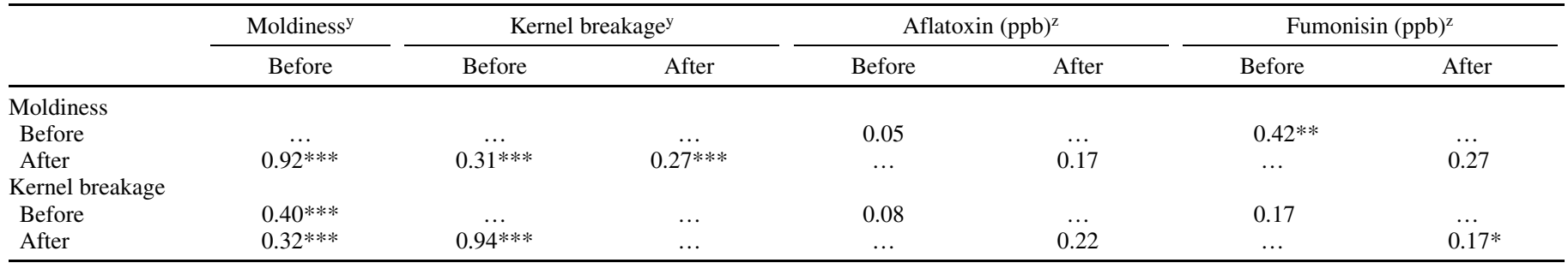

x Asterisks: *,**, and *** represent significance of the correlation coefficient at $\alpha=0.05,0.01$, and 0.001 , respectively.

y Trained research assistants scored grain for moldiness and kernel breakage prior to collection of milled samples of the sorted grain during a cross-sectional survey in Eastern Kenya in 2010. Grain was scored before and after sorting using a 1-to-5 score scale as follows: $1=<1,2=1$ to $10,3=10$ to $50,4=50$ to 90 , and $5=>90 \%$ broken or moldy, discolored, or rotten kernels in a sample.

${ }^{\mathrm{z}}$ Paired unsorted and sorted grain samples $(n=51)$ were collected from posho mills $(n=5)$ within an aflatoxin hotspot area: Machakos district in eastern Kenya in 2012. Grain was scored using the described scale. Mycotoxins were analyzed using enzyme-linked immunosorbent assay.

TABLE 6. Pairwise comparisons of means of grain quality scores and mycotoxin levels before and after visual sorting

\begin{tabular}{|c|c|c|c|c|c|c|}
\hline Qualities, mycotoxins & $d f$ & Mean BS ( \pm SE) & Mean AS $( \pm$ SE) & Mean difference & $t$ ratio & $\mathrm{P}>|t|$ \\
\hline Moldiness $^{y}$ & 810 & $1.45( \pm 0.01)$ & $1.44( \pm 0.01)$ & -0.01 & -1.02 & 0.308 \\
\hline Kernel breakage $\mathrm{e}^{\mathrm{y}}$ & 810 & $1.35( \pm 0.01)$ & $1.33( \pm 0.01)$ & -0.02 & -3.35 & 0.0008 \\
\hline Aflatoxin $(\mathrm{ppb})^{\mathrm{z}}$ & 50 & $15.9( \pm 5.5)$ & $15.4( \pm 5.4)$ & -0.6 & -0.071 & 0.943 \\
\hline Fumonisin $(\mathrm{ppb})^{\mathrm{z}}$ & 50 & $1,386.0( \pm 189)$ & $487.0( \pm 185)$ & 900 & -3.402 & 0.001 \\
\hline
\end{tabular}

y Grain were scored for moldiness and kernel breakage before and after sorting (BS and AS, respectively) using a 1 -to- 5 score scale, where $1=<1,2=1$ to $10,3=$ 10 to $50,4=50$ to 90 , and $5=>90 \%$ broken, moldy, discolored, or rotten kernels in a sample. SE = standard error. Scoring was done by trained research assistants using the same grain quality pictorial guides employed during a cross-sectional survey in eastern Kenya in 2010.

${ }^{\mathrm{z}}$ Mycotoxins were quantified from samples $(n=51)$ that were collected from posho mills $(n=5)$ in within aflatoxin hotspot area Machakos district, in eastern Kenya in 2012. Data for samples with fumonisin level $>6,000$ ppb was excluded. 
proportion of self-provisioned maize was previously reported for eastern Kenya (59\% in 2006 and 100\% in 2007) (13). In the semisubsistence maize system typical of east Africa, the local hammer mill is often the only site of value addition in the system, and it has been reported that $\approx 60 \%$ of Kenyan maize is processed at these mills, with the remaining maize processed at larger mills or consumed in whole-grain preparations (26). Our personal observations suggest that home-grown maize is mainly processed at posho mills, with very little home-based milling. Thus, posho mills can permit surveillance and application of mycotoxin strategies in maize destined for immediate human consumption.

Our study reveals alarmingly high proportions of samples above the regulatory limit for the two toxins across eastern Kenya. We provide data on the prevalence and inferences regarding the drivers of aflatoxin contamination. The study design, involving collection of samples and survey responses at posho mills, presents obvious weaknesses with regard to analysis of drivers. First, the design could not differentiate between pre- and postharvest aflatoxin drivers. Second, inferences regarding drivers relied on responses to questionnaires presented to posho mill customers, whereas the individuals interviewed may not have perfect knowledge or recollection of these factors. Nonetheless, the findings of our statistical analysis appear credible and relevant in aflatoxin management, and this design allowed us to enabling us to report on a wider geographical area than has been included in previous studies. This study was conducted in the year with second highest amount of rainfall since the last worst known acute fatal poisoning case, in 2004 , and complements the previous studies with more factors (both pre- and postharvest drivers) and insights into maize contamination (Table 7).

In this dataset, districts with the subhumid AEZ had the highest proportion of aflatoxin contamination, followed by the districts representing the semiarid zone. The subhumid AEZ was predominantly represented by samples collected from the three Meru districts in the upper eastern Kenya, where no cases of aflatoxicosis have been reported (13). The Meru districts had the highest proportion of samples contaminated above the legal limit, the highest mean aflatoxin levels, and the highest variance in aflatoxin levels. The subhumid regions of Meru region are not drought-prone, and the maize harvest in 2010 was bounteous. Therefore, the high levels of aflatoxin recorded in this study were not likely to be attributable to preharvest moisture stress but, rather, to poor drying and storage conditions. The subhumid AEZ is characterized by erratic weather conditions, and should also be

\section{四Aflatoxin $\equiv$ Fumonisin}

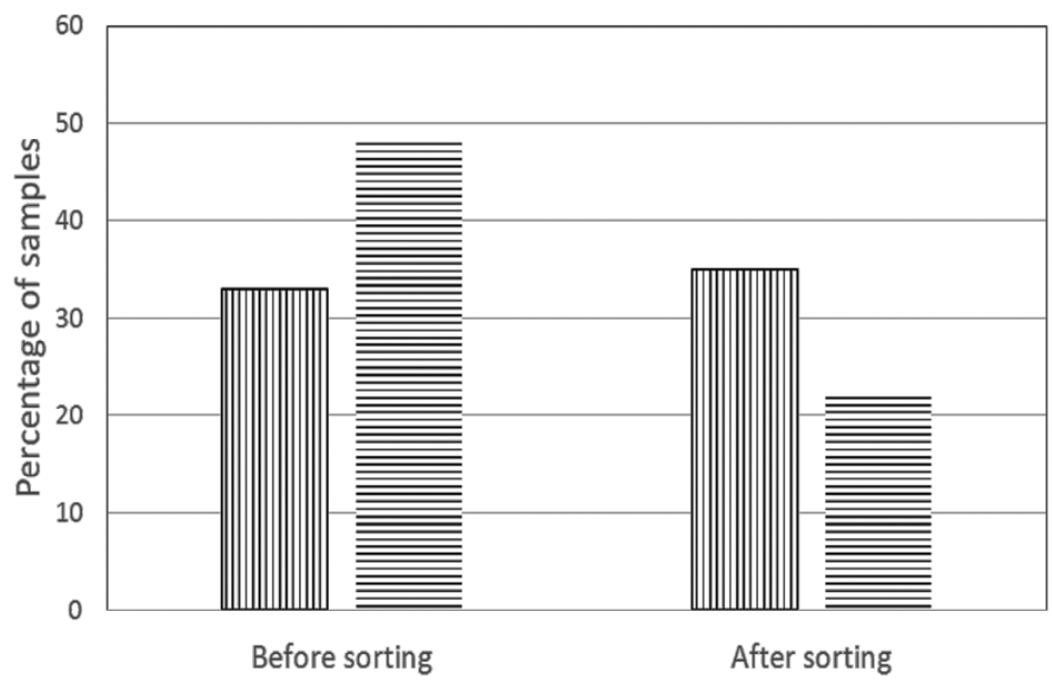

Fig. 5. Percentage of samples with mycotoxin above limits allowed in human food before and after grain sorting. Mycotoxins were quantified from samples $(n=$ 62) that were collected from posho mills $(n=5)$ in aflatoxin hotspot area Machakos district, in eastern Kenya in 2012. Data include samples with fumonisin level $>6,000 \mathrm{ppb}$.

TABLE 7. Chronology and conditions for aflatoxin contamination of maize in eastern Kenya

\begin{tabular}{|c|c|c|c|c|c|c|c|c|}
\hline Year $^{\mathrm{u}}$ & \multicolumn{2}{|c|}{ Rainfall $(\mathrm{mm})^{\mathrm{v}}$} & Outbreak & Districts $^{w}$ & Aflatoxin $(\mathrm{ppb})^{\mathrm{x}}$ & $\mathrm{AEZs}^{\mathrm{y}}$ & Factors $\mathrm{z}^{\mathrm{z}}$ & Reference \\
\hline $2003-2004$ & 678 & 395 & Yes & $3 \mathrm{LE}, \mathrm{I}$ CK; $n=350 ; \mathrm{fc}=125$ & $46,400(52.91)$ & $\begin{array}{l}\text { 2, Semiarid and semihumid to } \\
\text { semiarid }\end{array}$ & $\mathrm{PH}$ & $3,30,36$ \\
\hline 2004-2005 & 518 & 349 & Yes & $2 \mathrm{LE} ; n=298 ; \mathrm{fc}=?$ & $48,000(12.92)$ & 1, Semiarid & $\mathrm{PH}$ & 13 \\
\hline $2005-2006$ & 700 & 334 & Yes & $2 \mathrm{LE} ; n=165 ; \mathrm{fc}=53$ & $24,400(26.03)$ & 1, Semiarid & $\mathrm{PH}$ & 13 \\
\hline 2006-2007 & 961 & 640 & No & $2 \mathrm{LE} ; n=253 ; \mathrm{fc}=?$ & $2,500(1.95)$ & 1, Semiarid & $\mathrm{PH}$ & 13 \\
\hline $2007-2008$ & 601 & 372 & No & $2 \mathrm{LE}$ & 136 (NA) & 1, Semiarid & $\mathrm{PH}$ & 27 \\
\hline
\end{tabular}

u Bimodal rainfall, short season, October to February; long season, March to July. Short-season rainfall is more reliable for crop production in the region.

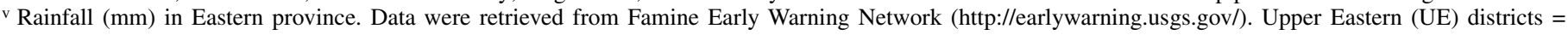
Meru north, Meru central, Meru south, Tharaka, Mbeere, and Embu. Lower Eastern (LE) districts = Machakos, Makueni, Kitui, and Mwingi.

${ }^{w}$ Number of districts; $\mathrm{CK}=$ Central Kenya; $n=$ sample size, $\mathrm{fc}=$ fatality cases, and $?=$ no report of fatal aflatoxicosis .

${ }^{x}$ Maximum and geometric mean (GM). NA = not reported.

y Number of agroecological zones (AEZs).

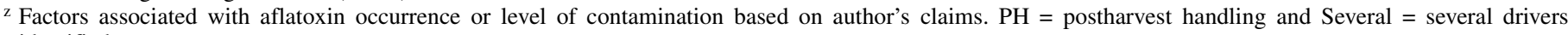
identified. 
considered in surveillance and management efforts. Efforts to address this expanded hotspot must include both attention to preharvest stress and to improving drying and storage conditions. Although previous studies have described postharvest grain handling as the major cause of contamination and aflatoxicosis, this study reports other factors such as size of the farm, grain yield, and intercropping to be associated with the problem. There is need for consistent season-to-season mycotoxin surveillance and analysis of drivers to facilitate better response to protect public health and knowledge of management strategies.

A lower proportion of aflatoxin contamination was observed in samples from farmers who grew their maize in an intercrop. Cultivation of maize in an intercrop system is a common practice in eastern Kenya (23). Previous reports on the influence of intercropping on aflatoxin contamination have been inconsistent. Tédihou et al. (43) observed that intercropping maize with cowpea reduced aflatoxin in stored maize, whereas Hell (18) observed a higher likelihood of aflatoxin contamination when maize was intercropped with cowpea. Intercropping has been documented to reduce plant disease pressure. In support of their observation, Tédihou et al. (43) argued that intercropping protects the host crop by providing a barrier to inoculum spread. An additional mechanism through which intercropping could have reduced aflatoxin accumulation is via improved soil fertility, because nutrient stress is a known driver of aflatoxin susceptibility in maize $(4,8)$. We acknowledge a need for follow-up experiments to confirm the effect of intercropping on mycotoxins, to investigate the mechanisms, and to assess the effects of crop species used in the intercrop system.

The current finding that farmers with larger maize farms and higher grain yield had lower likelihood of having contaminated maize could be explained in two ways. First, stress during crop growth has been positively correlated with aflatoxin levels (11, 17). Farmers with larger parcels of land and with higher yield returns can afford better crop production inputs that effectively manage preharvest stress-related vulnerability factors, and may have better postharvest handling and storage facilities that prevent further deterioration of produce. Use of insecticides and fertilizers have been documented to reduce aflatoxin contamination in certain contexts (7). Second, farmers with larger harvests have a wider choice of what grain to consume, could be more rigorous in sorting, and may sell what they perceive to be lower quality grain; therefore, they would not bring this through the posho mill for milling.

Maize with the most broken kernels was found to be most contaminated with aflatoxin. This presumably reflects the greater fragility of grain that has been colonized by fungi. In contrast, apparent moldiness and periharvest maize ear damage were not correlated with aflatoxin contamination. Previous studies have reported an increase in aflatoxin contamination with maize damage by insects $(25,51,52)$. Susceptibility of maize to infection by $A$. flavus and aflatoxin contamination was reported to increase with different forms of maize ear and kernel damage (37). Kernel breakage creates an infection court for the opportunistic pathogen (11). It is difficult to reconcile with existing knowledge the observation that farmers who had the least perceived periharvest maize ear damage had the most contaminated maize, and that the least aflatoxin contamination was associated with the worst periharvest ear damage. It should be noted that the sample size for the group perceived to have fewer damaged ears than usual was relatively small $(n=14)$ compared with that for ears that were perceived to have had more damage than usual $(n=254)$. The latter findings are likely if farmers with perceived higher periharvest damage sorted their maize immediately after harvest, as opposed to those who thought that their maize was clean. An immediate postharvest removal of damaged maize ears was reported to have reduced aflatoxin contamination (20). However, if farmers shelled their grain before sorting, then the process would not remove aflatoxin because our current study shows no correlation between apparent moldiness and aflatoxin.

This study reports a strong correlation between visually apparent moldiness and fumonisin, and concurs with previous studies that reported positive correlations between the toxin and kernel or ear rot $(2,39)$. We further show that grain sorting reduced fumonisin from above to far below the limit acceptable in human food. These findings imply that Kenyan maize consumers can effectively use their visual assessment to remove moldy grain and, hence, significantly lower the fumonisin contamination burden in their maize. F. verticillioides kernel rot is restricted to the pericarp, and the starburst symptoms are well correlated with fumonisin production (14). In contrast, we did not detect a difference between sorted and unsorted samples for aflatoxin. This could be because aflatoxin level was not reduced by grain sorting, or because the effect of sorting was overwhelmed by sampling error. We speculate that both of these factors contributed to our observations. It is known that A. flavus colonization can be internal to a maize kernel, hindering the effectiveness of visual inspection (41). The extreme skewness of aflatoxin contamination among individual kernels within a maize sample means that our design was not powerful for detecting the effect of sorting; it would have been more relevant to test the accepted and rejected kernels after sorting.

Although the high proportion of aflatoxin-contaminated maize was expected in this region, this study provides the first report of maize contamination by fumonisin in eastern Kenya $(13,21)$. The low correlation observed between aflatoxin and fumonisin suggests that management efforts should be focused on both mycotoxins. Because drivers for fumonisin were not assessed in this study, a detailed survey is now required to establish the factors associated with the widespread fumonisin contamination.

In conclusion, we have provided evidence that aflatoxin and fumonisin are major threats to the maize-consuming populations in eastern Kenya. Further, we have identified the major factors that drive aflatoxin presence and accumulation. Some of the factors identified to influence aflatoxin accumulation can be mitigated using inexpensive and sustainable approaches. For example, if intercropping is validated through experimentation to reduce aflatoxin, small-scale farmers could be advised to practice intercropping of maize with leguminous crops. This would not only reduce likelihood of aflatoxin-contamination but also improve soil nutrient levels and provide an alternative dietary source, which subsequently reduces exposure to aflatoxin and fumonisin if less maize is eaten. Creation of awareness of grain sorting as a method to reduce exposure to fumonisin, or an alternative use for the moldy and mycotoxin-contaminated maize, would serve best to manage the mycotoxin problem if effective grain sorting methods were in place.

\section{ACKNOWLEDGMENTS}

Financial support was provided by Atkinson's Center for Sustainable Future (ACSF); Cornell International Institute for Food, Agriculture and Development (CIIFAD) through its Stimulating Agricultural and Rural Transformation (StART) initiative; the Australian Agency for International Development (AusAID) through Biosciences Eastern and central Africa-International Livestock Research Institute (BecA-ILRI) Hub. Significant price discounts on mycotoxin analysis kits from Helica Biosystems, Inc. allowed greater sample sizes than would otherwise have been feasible. We thank research assistants who contributed to aspects of this study; the Kenyan authorities for permission and other forms of guidance that facilitated this work; and R. Darnell (Commonwealth Scientific and Industrial Research Organization, CSIRO, Australia) and F. Vermeylen (Cornell University, Ithaca, NY) for statistical advice offered.

\section{LITERATURE CITED}

1. Afolabi, C. G., Bandyopadhyay, R., Leslie, J. F., and Ekpo, E. J. A. 2006. Effect of sorting on incidence and occurrence of fumonisins and 
Fusarium verticillioides on maize from Nigeria. J. Food Prot. 69:20192023.

2. Alakonya, A. E., Monda, E. O., and Ajanga, S. 2008. Effect of delayed harvesting on maize ear rot in western Kenya. Am. Euras. J. Agric. Environ. Sci. 4:372-380.

3. Azziz-Baumgartner, E., Lindblade, K., Gieseker, K., Rogers, H. S., Kieszak, S., Njapau, H., Schleicher, R., McCoy, L. F., Misore, A., DeCock, K., Rubin, C., and Slutsker, L. 2005. Case-control study of an acute aflatoxicosis outbreak, Kenya, 2004. Environ. Health Persp. 113:1779-1783. doi:10.1289/ehp.8384

4. Bauer, P. J., and Carter, P. R. 1986. Effect of seeding date, plant-density, moisture availability, and soil-nitrogen fertility on maize kernel breakage susceptibility. Crop Sci. 26:1220-1226.

5. Bétran, F. J., and Isakeit, T. 2004. Aflatoxin accumulation in maize hybrids of different maturities. Agron. J. 96:565-570.

6. Bétran, J., Isakeit, T., Odvody, G., and Mayfield, K. 2005. Breeding corn to reduce preharvest aflatoxin contamination. Pages 353-377 in: Aflatoxin and Food Safety. H. K. Abbas, ed. CRC Press LLC, Boca Raton, FL.

7. Blandino, M., Reyneri, A., and Vanara, F. 2008. Influence of nitrogen fertilization on mycotoxin contamination of maize kernels. Crop Prot. 27:222-230. doi:10.1016/j.cropro.2007.05.008

8. Bowen, G. D. 1980. Misconceptions, concepts and approaches in rhizosphere biology. In: Contemporary Microbial Ecology. D. C. Ellwood, J. N. Hedger, M. J. Latham, and J. M. Lynch, eds. Academic Press Inc., London.

9. Byerlee, D., and Eicher, C. K. 1997. Africa's Emerging Maize Revolution. Lynne Rienner Publishers, Inc., Boulder, CO.

10. CAST. 2003. Mycotoxins: Risks in Plant, Animal, and Human Systems. In: Task Force Reports. Council of Agricultural Research and Technology, Ames, IA.

11. Chen, Z. Y., Brown, R. L., and Cleveland, T. E. 2004. Evidence for an association in corn between stress tolerance and resistance to Aspergillus flavus infection and aflatoxin contamination. Afr. J. Biotechnol. 3:693699.

12. Chulze, S. N. 2010. Strategies to reduce mycotoxin levels in maize during storage: A review. Food Addit. Contam. Part A: Chem. Anal. Control Expo. Risk Assess. 27:651-657. doi:10.1080/19440040903573032

13. Daniel, J. H., Lewis, L. W., Redwood, Y. A., Kieszak, S., Breiman, R. F., Flanders, W. D., Bell, C., Mwihia, J., Ogana, G., Likimani, S., Straetemans, M., and McGeehin, M. A. 2011. Comprehensive assessment of maize aflatoxin levels in Eastern Kenya, 2005-2007. Environ. Health Persp. 119:1794-1799. doi:10.1289/ehp.1003044

14. Duncan, K. E., and Howard, R. J. 2010. Biology of maize kernel infection by Fusarium verticillioides. Mol. Plant-Microbe Interact. 23:6-16. doi:10.1094/mpmi-23-1-0006

15. Friesen, D. K., and Palmer, A. F. E., eds. 2002. Integrated approaches to higher maize productivity in the new millennium. Pages 10-20 in: Proc. 7th East. South. Afr. Regional Maize Conf. Nairobi, Kenya. CIMMYT, Mexico.

16. Gelderblom, W. C. A., Marasas, W. F. O., Lebepe-Mazur, S., Swanevelder, S., Vessey, C. J., and Hall, P. D. 2002. Interaction of fumonisin $B_{1}$ and aflatoxin $\mathrm{B}_{1}$ in a short-term carcinogenesis model in rat liver. Toxicology 171:161-173. doi:10.1016/s0300-483x(01)00573-x

17. Guo, B. Z., Chen, Z. Y., Lee, R. D., and Scully, B. T. 2008. Drought stress and preharvest aflatoxin contamination in agricultural commodity: Genetics, genomics and proteomics. J. Integr. Plant Biol. 50:1281-1291. doi:10.1111/j.1744-7909.2008.00739.x

18. Hell, K. 1997. Factors Contributing to the Distribution and Incidence of Aflatoxin Producing Fungi in Stored Maize in Benin. University of Hannover, Germany.

19. Hell, K., Fandohan, P., and Cardwell, K. F. 2003. Development of management options for the control of aflatoxin in maize in West Africa. Pages 468-474 in: Advances in Stored Product Protection. Proc. 8th Int. Working Conf. Stored Product Prot. P. F. Credland, D. M. Armitage, and C. H. Bell, eds. Cambridge, MA

20. Hell, K., Fandohan, P., Kiewnick, S., Sikora, R., and Cotty, P. J. 2008. Pre- and postharvest management of aflatoxin in maize: An African perspective. Pages 219-229 in: Mycotoxins: Detection Methods, Management, Public Health and Agricultural Trade. J. F. Leslie, R. Bandyopadhyay, and A. Visconti, eds. CABI, Wallingford, UK.

21. Hell, K., and Mutegi, C. 2011. Aflatoxin control and prevention strategies in key crops of Sub-Saharan Africa. Afr. J. Microbiol. Res. 5:459-466.

22. Jaetzold, R., and Schmidt, H. 1982. Farm Management Handbook of Kenya. Part A: West Kenya (Nyanza and Western Provinces), 1st ed. Vol. II, Natural Conditions and Farm Management Information. Ministry of Agriculture, Nairobi, Kenya.

23. Jaetzold, R., Schmidt, H., Hornetz, B., and Shisanya, C. 2006. Farm Management Handbook of Kenya. Part C: East Kenya. 2nd ed. Vol. II, Natural Conditions and Farm Management Information. Ministry of Agriculture, Nairobi, Kenya.
24. Kaaya, A. N., and Kyamuhangire, W. 2010. Drying maize using biomassheated natural convection dryer improves grain quality during storage. J. Appl. Sci.:967-974.

25. Kaaya, A. N., Warren, H. L., Kyamanywa, S., and Kyamuhangire, W. 2005. The effect of delayed harvest on moisture content, insect damage, moulds and aflatoxin contamination of maize in Mayuge district of Uganda. J. Sci. Food Agric. 85:2595-2599. doi:10.1002/jsfa.2313

26. Kang'ethe, E. 2011. Situation analysis: Improving food safety in the maize value chain in Kenya. In: National Stakeholders Workshop on Aflatoxin Control Along the Maize Value Chain in Kenya. Food and Agriculture Organization (FAO), Nairobi, Kenya.

27. Kankolongo, M. A., Hell, K., and Nawa, I. N. 2009. Assessment for fungal, mycotoxin and insect spoilage in maize stored for human consumption in Zambia. J. Sci. Food Agric. 89:1366-1375. doi: $10.1002 /$ jsfa. 3596

28. Kimanya, M. E., De Meulenaer, B., Tiisekwa, B., Ndomondo-Sigonda, M., Devlieghere, F., Van Camp, J., and Kolsteren, P. 2008. Co-occurrence of fumonisins with aflatoxins in home-stored maize for human consumption in rural villages of Tanzania. Food Addit. Contam. Part A Chem. Anal. Control Expo. Risk Assess. 25:1353-1364. doi: $10.1080 / 02652030802112601$

29. Lewis, L., Onsongo, M., Njapau, H., Schurz-Rogers, H., Luber, G., Kieszak, S., Nyamongo, J., Backer, L., Dahiye, A. M., Misore, A., DeCock, K., Rubin, C., and Kenya Aflatoxicosis Investigation Group. 2005. Aflatoxin contamination of commercial maize products during an outbreak of acute aflatoxicosis in eastern and central Kenya. Environ. Health Persp. 113:1763-1767. doi:10.1289/ehp.7998

30. Liu, Y., and Wu, F. 2010. Global burden of aflatoxin-induced hepatocellular carcinoma: A risk assessment. Environ. Health Persp. 118:818824. doi:10.1289/ehp.0901388

31. MacArthur, R., MacDonald, S., Brereton, P., and Murray, A. 2006. Statistical modelling as an aid to the design of retail sampling plans for mycotoxins in food. Food Addit. Contam. 23:84-92. doi:10.1080/ 02652030500306927

32. Mundt, C. C. 2002. Use of multiline cultivars and cultivar mixtures for disease management. Annu. Rev. Phytopathol. 40:381-410.

33. Nelson, P. E., Desjardins, A. E., and Plattner, R. D. 1993. Fumonisins, mycotoxins produced by Fusarium species: Biology, chemistry, and significance. Annu. Rev. Phytopathol. 31:233-252.

34. Ngindu, A., Ocheng, D. M., Omondi, T. N., Ngare, W., Gatei, D., Johnson, B. K., Ngira, J. A., Nandwa, H., Jansen, A. J., Kaviti, J. N., and Siongok, T. A. 1982. Outbreak of acute hepatitis caused by aflatoxin poisoning in Kenya. Lancet 1:1346-1348.

35. Nyikal, J., Misore, A., Nzioka, C., Njuguna, C., Muchiri, E., Njau, J., Maingi, S., Njoroge, J., Mutiso, J., Onteri, J., Langat, A., Kilei, I. K., Nyamongo, J., Ogana, G., Muture, B., Tukei, P., Onyango, C., Ochieng, W., Tetteh, C., Likimani, S., Nguku, P., Galgalo, T., Kibet, S., Manya, A., Dahiye, A., Mwihia, J., Mugoya, I., Onsongo, J., Ngindu, A., DeCock, K. M., Lindblade, K., Slutsker, L., Amornkul, P., Rosen, D., Feiken, D., Thomas, T., Mensah, P., Eseko, N., Nejjar, A., Onsongo, M., Kessel, F., Njapau, H., Park, D. L., Lewis, L., Luber, G., Rogers, H., Backer, L., Rubin, C., Gieseker, K. E., Azziz-Baumgartner, E., Chege, W., and Bowen, A. 2004. Outbreak of aflatoxin poisoning-Eastern and Central Provinces, Kenya, January-July 2004. Pages 790-793 in: Morbidity and Mortality Weekly Report. Center for Disease Control and Prevention (CDC), Atlanta, GA

36. Nyoro, J. K., Kiiru, M. W., and Jayne, T. S. 1999. Evolution of Kenya's maize marketing systems in the post liberalization era. In: 4th Agric. Transformation Workshop. Tegemeo Institute of Agricultural Policy and Development, Egerton University, Njoro, Nairobi, Kenya.

37. Payne, G. A., and Yu, J. 2010. Ecology, Development and Gene Regulation in Aspergillus flavus. In: Aspergillus: Molecular Biology and Genomics. M. G. K. Machida, ed. Caister Academic Press, Norfollk, UK.

38. Probst, C., Schulthess, F., and Cotty, P. J. 2010. Impact of Aspergillus section Flavi community structure on the development of lethal levels of aflatoxins in Kenyan maize (Zea mays). J. Appl. Microbiol. 108:600-610. doi:10.1111/j.1365-2672.2009.04458.x

39. Robertson, L. A., Kleinschmidt, C. E., White, D. G., Payne, G. A., Maragos, C. M., and Holland, J. B. 2006. Heritabilities and correlations of Fusarium ear rot resistance and fumonisin contamination resistance in two maize populations. Crop Sci. 46:353-361. doi:10.2135/ cropsci2005.0139

40. Shephard, G. S. 2008. Impact of mycotoxins on human health in developing countries. Food Addit. Contam. 25:146-151. doi:10.1080/ 02652030701567442

41. Smart, M. G., Shotwell, O. L., and Caldwell, R. W. 1990. Pathogenesis in Aspergillus ear rot of maize-aflatoxin $\mathrm{B}_{1}$ levels in grains around woundinoculation sites. Phytopathology 80:1283-1286. doi:10.1094/Phyto-801283 
42. Sweeney, D. W., and Jardine, D. J. 2004. Nitrogen management in notillage and ridge-tillage systems affects short-season corn grown on claypan soil. Crop Manage. June:1-8.

43. Tédihou, E., Olatinwo, R., Hell, K., Hau, B., and Hoogenboom, G. 2012. Effects of variety, cropping system and soil inoculation with Aspergillus flavus on aflatoxin levels during storage of maize. Trop. Plant Pathol. 37:25-36.

44. van Egmond, H. P., Schothorst, R. C., and Jonker, M. A. 2007. Regulations relating to mycotoxins in food. Anal. Bioanal. Chem. 389:147-157. doi:10.1007/s00216-007-1317-9

45. Wagacha, J. M., and Muthomi, J. W. 2008. Mycotoxin problem in Africa: Current status, implications to food safety and health and possible management strategies. Int. J. Food Microbiol. 124:1-12. doi: 10.1016/j.ijfoodmicro.2008.01.008

46. Wang, Z., Liu, J., Lee, D., Scully, B., and Guo, B. 2008. Postharvest Aspergillus flavus colonization in responding to preharvest field condition of drought stress and oligo-macroarray profiling of developing corn kernel gene expression under drought stress. (Abstr.) Phytopathology 98:S166.

47. Wanzala, M., Jayne, T. S., Staatz, J. M., Mugera, A., Kirimi, J., and Owuor, J. 2001. Fertilizer Markets and Agricultural Production Incentives: Insights from Kenya. Tegemeo Institute of Agricultural Policy and Development, Egerton University, Njoro, Kenya.

48. Wiatrak, P. J., Wright, D. L., Marois, J. J., and Wilson, D. 2005. Influence of planting date on aflatoxin accumulation in $\mathrm{Bt}$, non-Bt, and tropical non-Bt hybrids. Agron. J. 97:440-445.

49. Williams, J. H., Grubb, J. A., Davis, J. W., Wang, J. S., Jolly, P. E., Ankrah, N. A., Ellis, W. O., Afriyie-Gyawu, E., Johnson, N. M., Robinson, A. G., and Phillips, T. D. 2010. HIV and hepatocellular and esophageal carcinomas related to consumption of mycotoxin-prone foods in sub-Saharan Africa. Am. J. Clin. Nutr. 92:154-160. doi:10.3945/ ajen.2009.28761

50. Williams, J. H., Phillips, T. D., Jolly, P. E., Stiles, J. K., Jolly, C. M., and Aggarwal, D. 2004. Human aflatoxicosis in developing countries: A review of toxicology, exposure, potential health consequences, and interventions. Am. J. Clin. Nutr. 80:1106-1122.

51. Williams, W. P., Windham, G. L., Buckley, P. M., and Perkins, J. M. 2005. Southwestern corn borer damage and aflatoxin accumulation in conventional and transgenic corn hybrids. Field Crops Res. 91:329-336. doi:10.1016/j.fcr.2004.08.002

52. Williams, W. P., Windham, G. L., Krakowsky, M. D., Scully, B. T., and $\mathrm{Ni}, \mathrm{X}$. Z. 2010. Aflatoxin accumulation in BT and non-BT maize testcrosses. J. Crop Improv. 24:392-399. doi:10.1080/15427528. 2010.505111 